\title{
EFEKTIVITAS PENGGUNAAN MEDIA PEMBELAJARAN MOBILE LEARNING BERBASIS ANDROID
}

\author{
Muhammad Faqih ${ }^{1)}$ \\ ${ }^{1}$ Pendidikan Bahasa dan Sastra Indonesia, Fakultas Ilmu Tarbiyah dan Pendidikan, Universitas Islam Negeri Syarif \\ Hidayatullah Jakarta, J1. Ir. H. Djuanda No.95, Ciputat, Tangerang Selatan, Banten 15412, Indonesia. \\ E-mail: muhammadelsyahid180@gmail.com
}

\begin{abstract}
Abstrak
Media pembelajaran adalah istrumen yang sangat menentukan keberhasilan proses belajar mengajar. Sebab keberadaannya secara langsung dapat memberikan dinamika tersendiri terhadap peserta didik. Perkembangan zaman menjadikan guru-guru turut aktif dan cermat dalam membuat media pembelajaran berbasis elektronik. Mobile learning adalah satu istilah yang dipakai untuk mengungkapkan model media pembelajaran yang mengadopsi perkembangan teknologi seluler sebagai sebuah media pembelajaran, dengan menyajikan gambar, audio, dan teks. Smart App Creator sebagai salah satu pranala membuat media berbasis mobile learning. Sehingga guru dapat membuat sebauh media yang berbasis android. Metode yang dipakai dalam penelitian ini yaitu, metode kualitatif deskriptif dengan model pengambilan data secara wawancara. Hasilnya, banyak orang yang memberikan tanggapan positif, yang artinya pembelajaran berbasis android itu sangat dibutuhkan. Tujuan dari penulisan jurnal ini, yaitu untuk memberikan pemaparan tentang efektivitas aplikasi yang penulis buat, agar dapat dipakai dalam pembelajaran di sekolah.
\end{abstract}

Kata Kunci: Media Pembelajaran; Smart App Creator; Mobile Learning.

\begin{abstract}
Learning media is an instrument that will determine the success of the teaching and learning process. Because its existence can directly provide its own dynamics to students. The times have made teachers participate actively and carefully in making electronic-based learning media. Mobile learning is a term used to describe a learning media model that adopts the development of cellular technology as a learning medium, by presenting images, audio, and text. Smart App Creator as a link to create mobile learning-based media. So that teachers can create an Android-based media. The method used in this research is descriptive qualitative method with interview data collection model. As a result, many people gave positive responses, which means that Android-based learning is very much needed. The purpose of writing this journal is to provide a description of the effectiveness of the application that the author made, so that it can be used in learning at school.
\end{abstract}

Keywords: Learning Media; Smart App Creator; Mobile Learning.

\section{PENDAhULUAN}

Perkembangan teknologi komunikasi dan informasi sudah sangat pesat terutama di Indonesia. Dalam dunia pendidikan, media adalah salah satu hal terpenting dalam menyukseskan kegiatan belajar mengajar (KBM). Media pembelajaran adalah sesuatu hal yang digunakan oleh guru untuk menyampaikan pengetahuan kepada muridmuridnya guna menarik siswa agar lebih tertarik dengan materi pelajaran tertentu. Ada beberapa batasan yang dibuat oleh para ahli dalam mengemukakan pengertian media pembelajaran, di antaranya yaitu ( $R, 1996)$ membatasi bahwa media adalah alat yang dapat membawa suatu informasi, yang dapat digunakan untuk pembelajaran atau yang bersangkutan dengan pembelajaran.

Selanjutnya, yaitu menurut (Azhar, 2003) Media dalam suatu pembelajaran sangatlah penting, guna menjadi sarana komunikasi antara komunikator (dalam hal ini pendidik) dan komunikan (peserta didik). Agar, apa yang disampaikan oleh pendidik, dapat diterima dengan baik oleh peserta didik. Menurut (Munadi, 2010), bahwa media adalah suatu alat penyalur pesan yang dirancang secara sistematis dan diambil dari sumber yang terancang pula, sehingga dapat menciptakan kegiatan belajar mengajar yang kondusif dan terstruktur. 
Ada beberapa macam media pembelajaran yang dapat digunakan dalam menyongsong kegiatan belajar mengajar. Satu diantaranya yaitu dengan mobile learning. Mobile learning adalah istilah dari satu model pembelajaran yang melibatkan perangkat bergerak, (Bambang, 2008) artinya peserta atau murid dapat mengakses materi pembelajaran petunjuk belajar dengan aplikasi pembelajaran di manapun dan kapanpun. Karena media ini tidak dibatasi dengan ruang dan waktu.

Semenjak Covid-19 melanda Indonesia pada awal tahun 2020, pemerintah menerapkan peraturan Pembatasan Sosial Bersekala Besar (PSBB) dan mewajibkan seluruh masyarakat untuk melakukan kegiatan sehari-harinya dari rumah. Tugas guru harus tetap mengajar walaupun dari rumah. Maka guru dituntut untuk menguasai media digital. Guru dituntut agar dapat membuat media pembelajaran berbasis digital agar efektif dan seinovatif mungkin, agar murid dapat tertarik dengan pembelajaran yang dibawakan oleh guru.

Seperti penelitian yang sebelumnya oleh ( $R$, 1996), dalam penelitian, mereka mengatakan bahwa ppertumbuhan pesat teknologi memberikan angin segar terhadap kegiatan pendidikan, termasuk di dalamnya kegiatan belajar mengajar, dan memudahkan para pengajar atau peserta didik memperoleh informasi, sehingga pembelajaran akan lebih efektif dan mengikuti perkembangan teknologi dan informasi. Selain itu, ada juga penelitian dari (Choiroh, 2020), dengan judul Efektifitas Pembelajaran Daring yang diterbitkan pada tahun 2020. mengemukakan bahwa penggunaan media pembelajaraan secara daring dapat menstimulus siswa untuk lebih meningkatkan kualitas dalam proses kegiatan belajar mengajar siswa. Penggunaan media pembelajaran yang dilakukan secara daring sangat banyak sekali memiliki manfaat, empat di antaranya: 1) proses kegiatan belajar mengajar tentu akan lebih menarik, 2) bahan pengajaran akan lebih jelas, sehingga siswa dapat menangkap pelajaran yang disampaikan oleh pendidik dengan baik, 3) metode yang dipakai oleh pendidik tentu akan lebih bervariatif, 4) siswa akan lebih aktif, karena tidak hanya mendengarkan guru yang sedang menjelaskan, tetapi siswa juga dapat dituntut aktif, untuk mendemostrasikan, dan lain-lain. Dari beberapa penelitian yang sudah dilakukan, dapat disimpulkan bahwa pembelajaran secara daring, itu sangatlah penting untuk pendidikan di tengah pesatnya perkembangan teknologi yang sangat cepat ini.

Satu diantara aplikasi yang dapat dipakai untuk membuat suatu media pembelajaran yaitu Smart App Creator. Smart App Creator adalah perangkat lunak yang dapat digunakan untuk membuat berbagai aplikasi-aplikasi multimedia berbasis mobile, desktop, dan web. Hal itu dikarenakan hasil akhir dari pengembangannya dapat dikonversikan menjadi beberapa basis aplikasi, yaitu Android, IoS, Desktop, dan Web HTML5 yang dapat diakses melalui browser. Dengan begitu, belajar tidak terikat oleh tempat dan waktu, artinya belajar dapat dilakukan di mana saja dan kapan saja. Mengingat penyebaran Covid-19 semakin tinggi yang juga akan mempengaruhi semakin panjangnya kegiatan belajar mengajar dilakukan secara daring. Oleh karenanya, pembahasan ini dianggap penting untuk diangkat, agar guru dapat membuat aplikasi media pembelajaran berbasis mobile learning dengan menggunakan Smart App Creator.

\section{KAJIAN LITERATUR}

\section{a. Media Pembelajaran}

Kata media berasal dari bahasa latin yang berarti medium, secara harfiah berarti 'perantara', 'penengah', dan 'pengantar'. Dalam proses pembelajaran, media merupakan perantara atau pengantar sumber pesan dengan penerima pesan, merangsang pikiran, perasaan, perhatian, dan kemauan yang mendorong proses pembelajaran. Senada dengan pendapat sebelumnya (Azhar, 2003) mengatakan bahwa secara garis besar media itu adalah manusia, materi, atau kejadian yang dapat mengingatkan kondisi yang dapat membuat siswa mampu memperoleh pengetahuan, keterampilan, dan sikap. 
Ada beberapa batasan media yang dikemukakan beberapa ahli, di antaranya Associationof Education Comunication Technology (AECT) memberikan definisi bahwa media merupakan segala bentuk dan saluran yang digunakan untuk proses penyampaian pesan. Sedangkan menurut (Kaltsum, 2017), media pembelajaran merupakan alat yang digunakan untuk menyampaikan isi materi pembelajaran yang dapat merangsang siswa dalam mengikuti proses pembelajaran.

Menurut (R, 1996) mengemukakan media adalah alat saluran komunikasi. Heninch mencontohkan media seperti film, televisi, diagram, computer dan instruktur. Sementara menurut (Karsono et al., 2014), mengatakan bahwa media pembelajaran adalah segala sesuatu (baik manusia, benda, ataupun lingkungan sekitar) yang dapat digunakan untuk menyampaikan atau menyalurkan pesan dalam mbelajaran sehingga dapat merangsang minat, perhatian, pikiran, dan perasaan siswa pada kegiatan belajar untuk mencapai tujuan. (Hamid, 2020)

Jadi, secara garis besar dapat disimpulkan bahwa media pembelajaran yaitu perangkat atau alat yang dipakai oleh guru dalam melakukan kegiatan belajar mengajar, guru juga dituntut agar media yang dibuatnya efektif, inofatif dan menarik, sehingga murid dapat tertarik mengikuti pembelajaran yang disampaikan oleh guru tersebut.

\section{b. Macam-macam media pembelajaran}

Berbicara tentang mecam-macam media pembelajaran yang ada di Indonesia tentu sangatlah banyak. Tetapi semua media yang ada tentu memiliki kelebihan dan kekurangannya masing-masing. Oleh karenannya, guru harus selektif dalam memilih media yang akan dipilihnya dalam mengajar.

Pada pembagian macam-macam media pembelajaran (Mahnun, 2012) dalam Sadiman menjelaskan bahwa media pembelajaran diklasifikasikan menjadi tujuh kelompok, antara lain: benda yang di demonstrasikan, media cetak, gambar diam, gambar bergerak, film bersuara, dan mesin belajar. (Hamidullah,
2017) Adapun menurut Allen, media itu diklasifikasikan menjadi sembilan kelompok, antara lain: visual diam, film, televisi, obyek tiga dimensi, rekaman, pelajaran terprogram, demonstrasi, buku teks cetak, dan sajian lisan. (Suging Pandu, 2014)

Selain itu, menurut Ely, media berdasarkan ciri fisiknya dikelompokkan menjadi delapan kelopmpok, antara lain presentasi verbal, presentasi grafis, gambar diam, gambar bergerak, rekaman suara, pengajara tipogram, dan simulasi. Namun, secara ukuran Ibrahim mengatakan bahwa berdasarkan alat dan perlengkapannya, media itu dikelompokkan menjadi lima kelompok, antara lain: media tanpa proyeksi dua dimensi; media tanpa proyeksi tiga dimensi; media audio; media proyeksi; televisi; video; komputer. (Hamidullah Ibda, 2017: 16).

Adapun menurut (Ramdani et al., 2018) media berdasarkan taksonomi itu dibagi menjadi delapan golongan, antara lain media audio; media cetak; media visual diam; media visual gerak; media semi gerak; media audio visual diam, dan media audio visual gerak. Namun, secara umum, Heninch membagi media menjadi tiga bagian, antara lain: pertama, media grafis, di dalamnya termasuk media visual, yang mana pesan yang akan disampaikan dituangkan ke dalam simbolsimbol komunikasi visual; kedua, media audia yang mana media ini berkaitan dengan indera pendengaran. Pesan-pesan yang akan disampaikan dituangkan ke dalam lambanglambang auditif, baik verbal maupun nonverbal; ketiga, media proyeksi diam, yang mana media ini mempunyai persamaan dengan media grafis, dalam artian sama-sama menyajikan rangsangan secaara visual. Sedangkan perbedaannya, media grafis dapat secara langsung dalam berinteraksi dengan pesan media yang bersangkutan (R, 1996)

\section{METODE PENELITIAN}

Metode yang dipakai dalam penelitian ini yaitu kuantitatif deskriptif, metode kuantitatif yakni meneliti dan menjabarkan sampel orangorang yang menggunakan media pembelajaran 
daring atau android, untuk menentukan seberapa efektivitas media pembelajaran berbasis daring atau android di kalangan pelajar.

Sedangkan metode deskkriptif yakni dengan menjelaskan pengertian media pembelajaran, macam-macam pembagiannya, serta menjelaskan bagaimana media pembelajaran berbasis android yang nantinya dapat diimplementasikan oleh guru-guru dalam melaksanakan kegiatan belajar mengajarnya.

\section{HASIL DAN PEMBAHASAN}

Salah satu model media pembelajaran yang dapat digunakan oleh guru yaitu mobile learning. Mobile learning adalah model pembelajaran yang memanfaatkan teknologi dan perangkat seluler. Hadhono dan Damayanti, dkk menggambarkan bahwa mobile learning merupakan model pembelajaran jarak jauh yang menggunakan teknologi komunikasi dan informasi. Kelebihan yang dapat diunggulkan model pembelajaran mobile learning, yakni siswa dapat belajar di mana pun dan kapan pun tanpa terikat tempat dan waktu. Clark Quinn mengemukakan mobile learning sebagai "The intersection of mobile computing and e-learning: accessible resources wherever you are, strong search capabilities, rich interaction, powerful support for effective learning, and performance-based assessment. E-Learning independent of location in time or space".

Ada beberapa kemampuan yang harus disediakan oleh perangkat pembelajaran mobile learning yakni adanya kemampuan untuk terkoneksi ke peralatan lain terutama komputer, kemampuan menyajikan informasi pembelajaran dan kemampuan untuk merealisasikan komunikasi antara pengajar dan pembelajar. Salah satu aplikasi yang dapat membuat aplikasi pembelajaran berbasis mobile yakni Smart App Creator.

Smart App Creator adalah suatu aplikasi yang dapat dipakai guru dalam membuat aplikasi-aplikasi multimedia berbasis mobile, desktop, dan web. Hal itu dikarenakan hasil akhir dari pengembangannya dapat dikonversikan menjadi beberapa basis aplikasi, yaitu Android, IoS, desktop, dan Web HTML5 yang dapat diakses melalui browser. Dengan begitu, belajar tidak terikat oleh tempat dan waktu, artinya belajar dapat dilakukan di mana saja dan kapan saja. Mengingat penyebaran Covid-19 semakin tinggi yang juga akan mempengaruhi semakin panjangnya kegiatan belajar mengajar dilakukan secara daring. Berikut ikon aplikasi Smart App Creator:

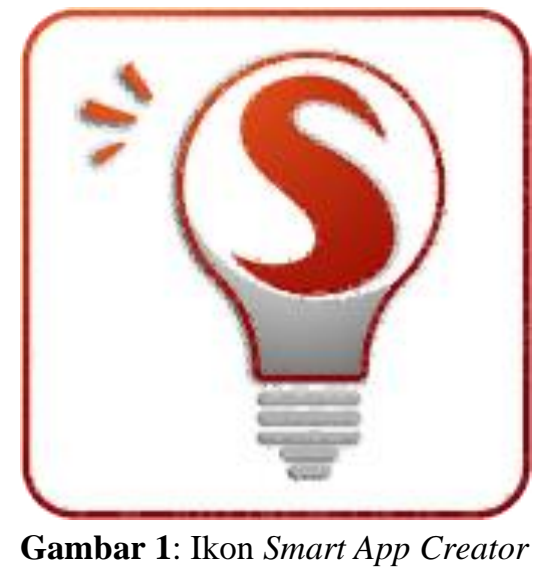

Gambar di atas adalah gambar dari ikon aplikasi Smart App Creator. Hal yang pertama yang harus dilakukan yaitu mengunduh aplikasi SAC di web.

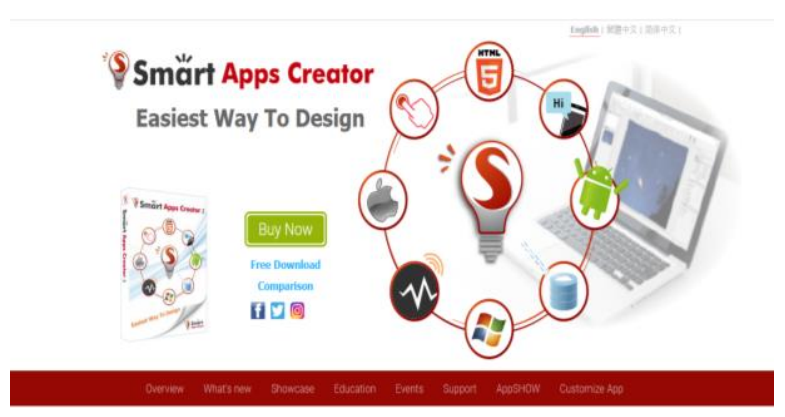

Gambar 2: Halaman awal Smart App Creator

Setelah mengunduh, kita dapat menginstal aplikasi tersebut ke dalam laptop kita, dan siap untuk membuat aplikasi pembelajaran. 


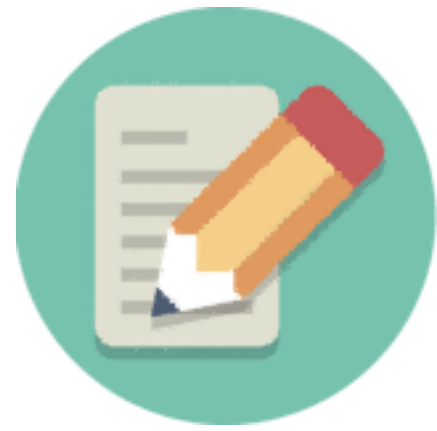

Gambar 3: Ikon aplikasi Media Pembelajaran Bahasa Indonesia

Gambar di atas adalah ikon dari aplikasi pembelajaran yang dibuat di Smart App Creator. Nama aplikasi tersebut adalah Media Pembelajaran B.I, yang di dalamnya dimuat pembelajaran tentang puisi, di antaranya definisi puisi, ciri-ciri puisi, usur-unsur pembentuk puisi, video pembacaan puisi, dan kuis mengenai pelajaran puisi. Aplikasi ini berbaisis android dan dapat dijalankan tanpa menggunakan jaringan internet.

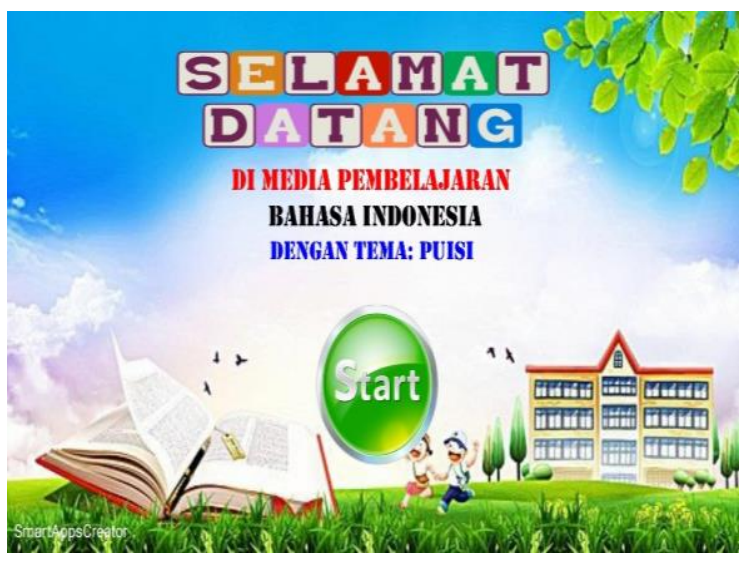

Gambar 4: Pembukaan aplikasi Media Pembelajaran B.I

Gambar di atas adalah pembukaan atau start aplikasi sebelum masuk ke dalam beranda aplikasi yang berisi beberapa pilihan.

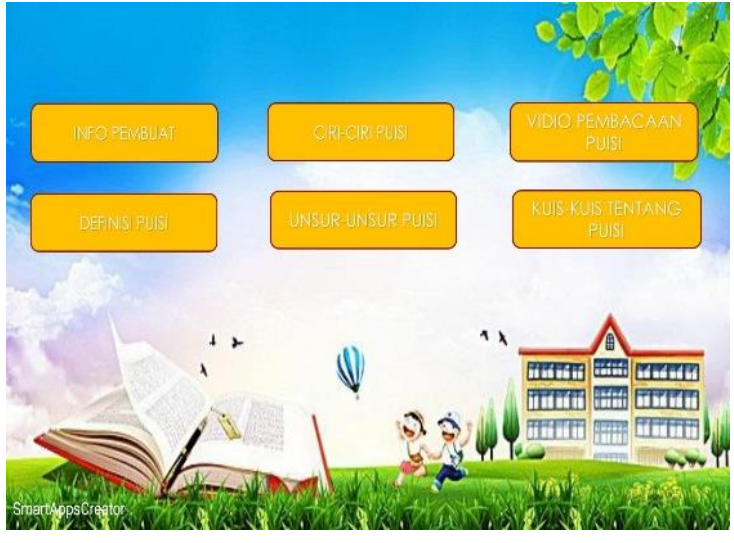

Gambar 5: Beranda aplikasi

Gambar di atas adalah beranda dari aplikasi Media Pembelajaran B.I beranda ini berisi dari berbagai pilihan, di antaranya yaitu Info Pembuat/Developer, definisi puisi, ciri-ciri puisi, unsur-unsur puisi, video pembacaan puisi, dan kuis tentang puisi.

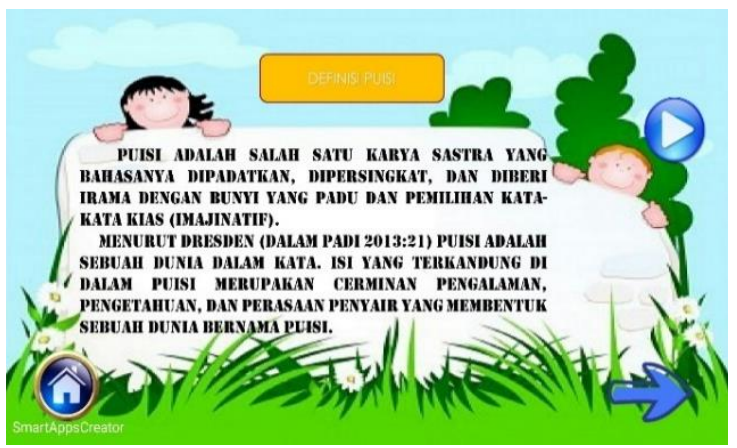

Gambar 6: Contoh materi ajar

Gambar di atas adalah salah satu contoh materi yang terdapat di apliakasi, dalam gambar tersebut terdapat dua media yang dipakai, yaitu media suara dan media tulis.

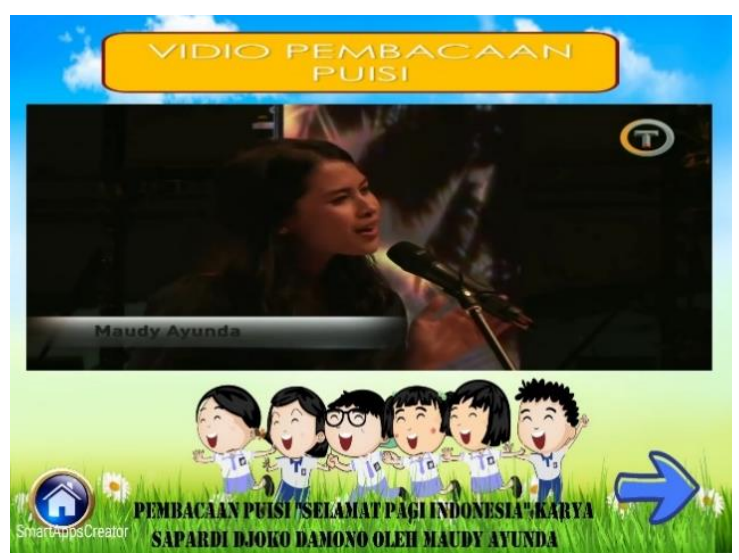


Gambar 7: Videopembacaan puisi oleh Maudy Ayunda

Gambar di atas adalah contoh video pembacaan puisi karya Sapardi Djoko Damono dengan judul Selamat Pagi Indonesia yang dibacakan Maudy Ayunda

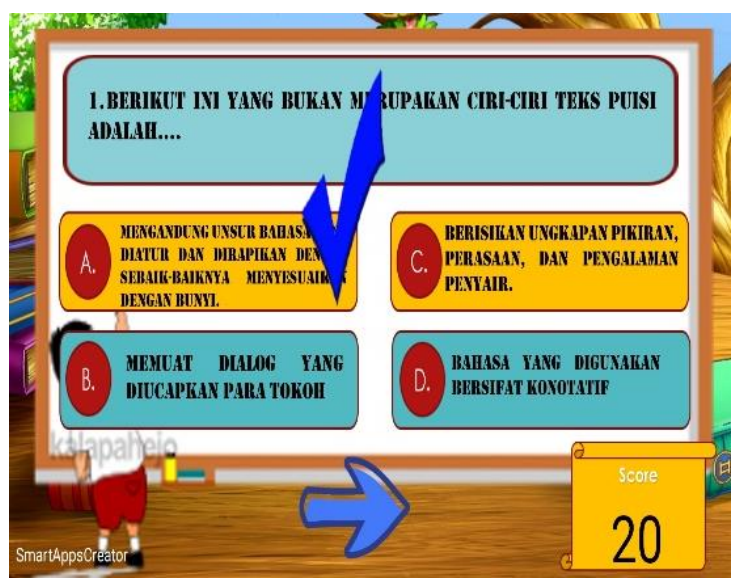

Gambar 8: Contoh kuis dalam aplikasi

Gambar di atas adalah contoh kuis yang ada di dalam aplikasi MP B.I, semua jawaban baik itu A,B,C,maupun D diberikan respon yaitu jika jawaban benar, maka akan mucul suara yang menandakan benar, lalu muncul gambar centang, dan nilai skornya bertambah.

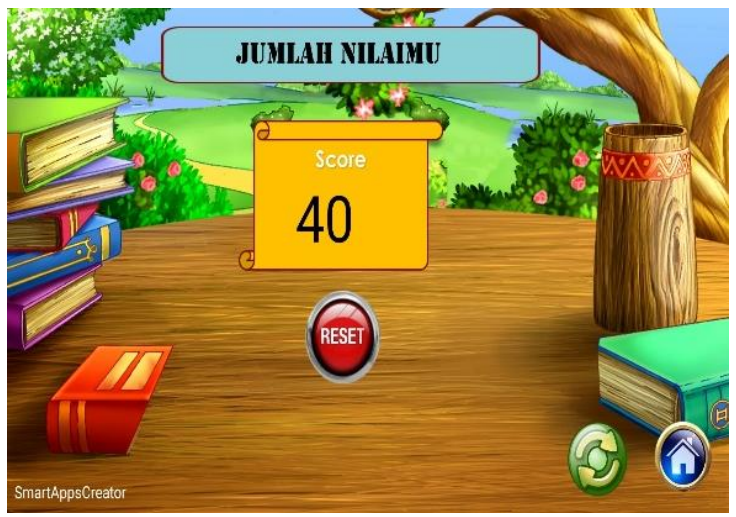

Gambar 9: Hasil skor nilai kuis

Gambar di atas adalah gambaran hasil skor dari jumlah jawaban yang benar. Jumlah soal ada 5 butir, tiap soal yang benar diberi nilai 20 . Jadi, apabila siswa benar semua dalam menjawab kuis, maka nilainya 100
Penggunaan media pembelajaran berbasis Mobile learning sangat dibutuhkan, terutama pada kondisi pandemic seperti akhir-akhir ini, yang mana semua pekerjaan, terutama pembelajaran dilakukan di rumah. Otomatis semua pekerjaan yang dilakukan di rumah, dikerjakan melalui daring/online. Maka dari itu, penulis akan meneliti seberapa efektif media berbasis mobile learning pada pembelajaran di sekolah. Berikut adalah data yang peneliti ambil dari beberapa orang dengan beberapa pertanyaan:

a. media apa yang sering digunakan temanteman selama pembelajaran jarak jauh?

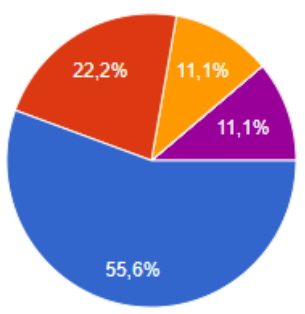

Google Clasroom Google Meet Zoom Meet WhatsApp Grup media lainnya

Dari hasil penelusuran pertanyaan di atas, dapat diketahui bahwa dari beberapa media yang dapat digunakan oleh guru pada masa pandemi di antaranya yaitu Google Clasroom, Google Meet, Zoom Meet, WhatsApp Group, atau media lainnya. yang paling banyak digunakan guru adalah Google Clasroom dengan presentase $55,5 \%$ artinya memang media GC sudah sangat popular sebagai media pembelajaran yang dipakai saat pembelajaran jarak jauh (PJJ).

b. Pernahkan guru teman-teman menggunakan media seperti dalam vidio berikut?

Dari penelusuran pertanyaan di atas, hampir seluruh respondenden menjawab tidak pernah, yang artinya, pembelajaran berbasis mobile learning sangat peru dikembangkan, mengingat semua kegiatan belajar mengajar dilakukan semua dari rumah.

c. jika diurutkan 10-100, berapakah yang teman-teman berikan untuk menilai media di atas? 

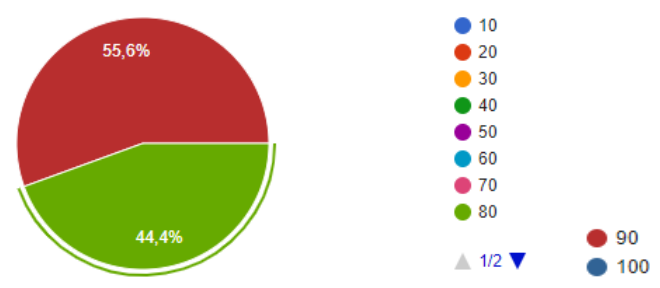

Dari hasil diagram tersebut, dapat diketahui bahwa penilaian media pembelajaran mobile learning sangat besar yakni dengan presentase $56 \%$ dengan nilai 90 dan $44 \%$ dengan nilai 90 yang artinya, murid sangat menginginkan media yang lebih modern dan mudah untuk diaplikasikan

d. menurut teman-teman, apakah media pembelajaran di atas menarik atau tidak. jika menarik apa alasannya? jika tidak menarik apa alasannya?

Dari hasil penelusuran peneliti, semua responden menjawab bahwa media pembelajaran mobile learning yang peneliti buat sangat menarik, dengan berbagai alasan. Menarik, karena dalam menyampaikan pesan (ilmu) media juga tentunya sangat berperan dalam menarik perhatian siswa agar siswa dapat mudah dalam memahami pesan yang disampaikan guru. Terlebih lagi dalam pembelajaran puisi, yang mana nada dan suasana menjadi salah satu unsur penting dalam membangun karya puisi. Oleh karenanya dengan adanya video pembacaan puisi akan menambah paham siswa apa itu nada dan suasana dalam menulis dan membaca puisi.

Dari hasil penelitian di atas, dapat disimpulkan bahwa media pembelajaran berbasis Mobile learning sangatlah penting untuk dikembangkan, mengingat perkembangan Ilmu Pengetahuan dan Teknologi (IPTEK) yang sangat cepat terutama juga dalam situasi pandemik yang mana semua kegiatan belajar mengajar dilakukan di rumah. Oleh karenanya, siswa sangat berharap sekali media pembelajaran mobile learning dapat dikembangkan agar guru-guru dalam menyampaikan ilmunya tidak monoton, dan tetap mengikuti perkembangan zaman.

\section{KESIMPULAN}

Perkembangan teknologi yang sangat pesat mempengaruhi proses kegiatan belajar mengajar dengan mengembangkan media pembelajaran daring berbasis Android atau $E$ Learning. Pembelajaran secara daring tentu memiliki banyak manfaat di antaranya: pembelajaran akan lebih menarik, dapat mencari bahan pelajaran dengan mudah, dan pembelajaran tentu akan lebih bervarisi. sehingga dapat menimbulkan pembelajaran yang efektif dan terstruktur dengan rapi.

\section{REFERENSI}

Azhar, A. (2003). Media Pembelajaran. In PT. Raja Grafindo Persada (p. 300). PT. Raja Grafindo Persada.

Bambang, W. (2008). Teknologi Pembelajaran Landasan \& Aplikasinya. In PT. Rineka Cipta (p. 208). PT. Rineka Cipta.

Choiroh, N. (2020). Efektivitas Pembelajaran Berbasis Daring / E-Learning Dalam Pandangan Siswa. In Institut Agama Islam Press (p. 150). Institut Agama Islam Press.

Hamid, M. A. (2020). Media Pembelajaran. In Yayasan Kita Menulis (p. 280). Yayasan Kita Menulis.

Hamidullah, I. (2017). Media Pembelajaran Berbasis Wayang. In CV. Pilar Nusantara (p. 270). CV. Pilar Nusantara.

Kaltsum, H. U. (2017). Pemanfaatan Alat Peraga Edukatif Sebagai Media Pembelajaran Bahasa Inggris Sekolah Dasar. Urecol: University Research Colloquium, 19-24.

Karsono, Sujana, Y., Daryanto, J., \& Yustinus, N. (2014). Penggunaan Kartu Kuartet Untuk Meningkat Pemahaman Keberagaman Seni Tradisi Nusantara Pada Siswa Sekolah Dasar. Jurnal Mimbar Sekolah Dasar, 1(1), 43-49.

Mahnun, N. (2012). Media Pembelajaran (Kajian terhadap Langkah-langkah Pemilihan Media dan Implementasinya dalam Pembelajaran). Jurnal Pemikiran Islam, 37(1), 27-35. 
Munadi, Y. (2010). Media Pembelajaran (Sebuah Pendekatan Baru). In Gaung Persada (GP) Press (p. 360). Gaung Persada (GP) Press.

R, H. (1996). Instructional Media and Tecnologies for Learning, 5 Edition. In Macmillan Publishing Company (p. 196). Macmillan Publishing Company.

Ramdani, R., Rahmat, M., \& Fakhruddin, A. (2018). Media Pembelajaran E-Learning Dalam Pembelajaran Pendidikan Agama Islam Di SMA Laboratorium Percontohan Upi Bandung. TARBAWY: Indonesian Journal of Islamic Education, 5(1), 4759. https://doi.org/10.17509/t.v5i1.13332

Suging Pandu, W. (2014). Media Pembelajaran dan Macam-macam Media Pembelajaran dalam Proses Belajar Mengajar. In Universitas Jember (p. 230). Universitas Jember. 